\title{
Impact of intima re-intrusion and expansion within 100 minutes on late lumen loss in percutaneous coronary intervention for diffuse in-stent restenosis
}

\author{
R lijima, Y Ikari, T Tsunoda, M Nakamura, K Hara, T Yamaguchi
}

Heart 2004;90:1071-1072. doi: 10.1136/hrt.2003.024042

$\mathrm{T}$ e recurrence of in-stent restenosis (ISR) is reported to be in the range of $20-40 \%$ but is especially high in diffuse ISR. ${ }^{1}$ Previous studies have shown that ISR is due solely to neointimal hyperplasia without stent recoil. ${ }^{2}$ ISR caused by neointimal proliferation frequently occurs within six months. However, the timing and mechanisms of recurrent ISR are unknown. A serendipitous observation revealed that lumen loss occurred during dwell time of radiation therapy of ISR by intravascular ultrasound (IVUS). ${ }^{3}$ However, mechanisms and roles of the acute lumen loss are unclear. This prospective study was undertaken to quantify lumen loss within minutes and to discuss the mechanism of recurrence in diffuse ISR.

\section{METHODS}

We prospectively enrolled 13 patients with 14 lesions, who underwent successful percutaneous coronary intervention (PCI) for treatment of diffuse ISR (lesion length $>10 \mathrm{~mm}$ ) in this study. All the patients gave informed consent. Quantitative coronary angiography (QCA) and IVUS were performed before, immediately after, and approximately 100 minutes after intervention. Cutting balloon angioplasty or balloon angioplasty was selected according to the discretion of the operator. A satisfactory angiographic result was defined as final residual stenosis $<25 \%$. All the patients had follow up angiography and follow up IVUS was performed in the nine patients that had angiographic restenosis. QCA was carried out in a routine manner. Minimal lumen diameter (MLD), reference diameter, diameter of stenosis (DS), and lesion length were measured using a single matched worst view. Late loss was defined as the MLD after the procedure minus the MLD at six months follow up.

IVUS was performed with an auto-motorised pullback at a speed of $0.5 \mathrm{~mm} / \mathrm{s}$. Cross sectional area (CSA) was traced manually. The stent, external elastic membrane (EEM), and lumen CSA were measured at three points (stent proximal and distal edge segment and the point of the narrowest lumen CSA inside the stent in the diastolic frames). Intima CSA was defined as the stent CSA minus lumen CSA. Intimal plus media CSA (I + M CSA) was defined as the EEM CSA minus lumen CSA. Continuous variables were compared by linear regression analysis and by paired Student's $t$ test. Data were expressed as mean (SD). A probability value of $p<0.05$ was considered significant.

\section{RESULTS}

The mean age of the patients was 66 (11) years and eight of the patients were men. Seven patients had diabetes mellitus $(54 \%)$. The repeat intervention was successful in all the patients without any complications. Six lesions were in the left anterior descending coronary artery, two lesions in the left main tract, and six lesions in the right coronary artery. Mean stent diameter was $3.2(0.4) \mathrm{mm}$ and mean stent length was 30 (15) mm. Ten patients (71\%) had repeat interventions for recurrent ISR. Eleven ISR lesions were treated by cutting balloon angioplasty and three by balloon angioplasty. Mean balloon to artery ratio was $1.2(0.2)$. Actual time of the second IVUS after successful intervention was 98 (44) minutes. Before intervention, reference diameter was 2.58 (0.45) mm, MLD 0.65 (0.45) mm, DS 75 (17\%), and lesion length measured 20.5 (14.5) $\mathrm{mm}$. Immediately after intervention, MLD increased to $2.24(0.38) \mathrm{mm}(\mathrm{p}<0.0001)$ and percentage DS decreased to $19.5(7.9 \%)(\mathrm{p}<0.0001)$. After 98 minutes, MLD and percentage DS tended to decrease (2.08 (0.27) mm, $23.4(6.2) \%$, respectively), but did not reach significance.

IVUS analysis is shown in table 1 : in the stent minimum lumen area (MLA), lumen CSA increased from $1.9(0.5) \mathrm{mm}^{2}$ before intervention to $7.2(1.9) \mathrm{mm}^{2}$, stent CSA increased from $8.9(2.2) \mathrm{mm}^{2}$ to $9.5(2.5) \mathrm{mm}^{2}$, and EEM CSA also increased from $18.4(5.0) \mathrm{mm}^{2}$ to 19.3 (4.8) $\mathrm{mm}^{2}$. At approximately 98 minutes after PCI, lumen CSA at stent MLA decreased from 7.2 (1.9) $\mathrm{mm}^{2}$ to 5.0 (1.4) $\mathrm{mm}^{2}$ $(\mathrm{p}<0.0001)$, and the EEM CSA also decreased at three points. However, there were no significant changes in stent CSA. In the MLA site, loss of lumen area in 98 minutes was 2.24 (1.1) $\mathrm{mm}^{2}$. However, lumen loss caused by EEM recoil was $0.49(0.39) \mathrm{mm}^{2}$. The unexplained difference was 1.76 (1.14) $\mathrm{mm}^{2}$. This is considered as tissue expansion.

Increase of intima CSA at 98 minutes positively correlated with increase of intima CSA at six months by IVUS $(r=0.49, \mathrm{p}=0.0006)$ and late lumen loss by QCA $(r=0.57, \mathrm{p}=0.0017)$. This indicates that $38 \%$ of the increase in intima CSA occurs within 98 minutes.

\section{DISCUSSION}

Restenosis is commonly observed between 3-6 months after PCI. However, our IVUS analysis revealed that a significant reduction of lumen CSA occurs within 98 minutes. This suggests that the mechanism of recurrence of diffuse ISR could be different. Since Sheran and colleagues ${ }^{3}$ considered $^{2}$ that total intima mass should remain constant, they regarded this lumen loss as "intima re-intrusion"—-that is, intima movement through the stent strut. However, our observations revealed that intima plus media CSA was not constant. Therefore, we propose a hypothesis that the intima temporarily shrinks like a sponge. A recent histological study showed that ISR consists of proteoglycan-rich tissue. ${ }^{4}$ Since proteoglycans are known to contain a lot of water, it is conceivable that ISR tissue acts like a sponge. One may argue that

Abbreviations: CSA, cross sectional area; DS, diameter of stenosis; EEM, external elastic membrane; ISR, in-stent restenosis; IVUS, intravascular ultrasound; MLA, minimum lumen area; $M L D$, minimal lumen diameter; $\mathrm{PCl}$, percutaneous coronary intervention; $\mathrm{QCA}$, quantitative coronary angiography 
Table 1 Intravascular ultrasound results.

\begin{tabular}{|c|c|c|c|c|c|}
\hline & Before PCI & Immediately after $\mathrm{PCI}$ & p Value & 98 mins after $\mathrm{PCl}$ & ${ }^{*} p$ Value \\
\hline \multicolumn{6}{|c|}{ Proximal stent edge $\left(\mathrm{mm}^{2}\right)$} \\
\hline Lumen CSA & $4.4(1.5)$ & $7.5(1.7)$ & 0.0001 & $6.6(1.6)$ & 0.01 \\
\hline Stent CSA & $9.3(2.8)$ & $9.8(2.8)$ & 0.02 & $10.1(3.1)$ & 0.93 \\
\hline EEM CSA & $18.3(4.4)$ & $19.4(4.8)$ & 0.02 & $18.9(4.5)$ & 0.02 \\
\hline I+M CSA & $13.9(4.3)$ & $11.7(4.2)$ & 0.0004 & $13.4(4.3)$ & 0.002 \\
\hline \multicolumn{6}{|c|}{ Stent MLA site $\left(\mathrm{mm}^{2}\right)$} \\
\hline Lumen CSA & $1.9(0.5)$ & $7.2(1.9)$ & $<0.0001$ & $5.0(1.4)$ & $<0.0001$ \\
\hline Stent CSA & $8.9(2.2)$ & $9.5(2.5)$ & $<0.01$ & $9.3(2.3)$ & 0.12 \\
\hline EEM CSA & $18.4(5.0)$ & $19.3(4.8)$ & 0.01 & $18.8(4.6)$ & $<0.01$ \\
\hline I+M CSA & $16.9(5.1)$ & $11.9(3.5)$ & $<0.0001$ & $14.4(4.2)$ & $<0.0001$ \\
\hline \multicolumn{6}{|c|}{ Distal stent edge $\left(\mathrm{mm}^{2}\right)$} \\
\hline Lumen CSA & $3.4(1.6)$ & $7.3(1.8)$ & 0.0001 & $6.4(1.7)$ & 0.03 \\
\hline Stent CSA & $8.8(2.8)$ & $9.6(2.5)$ & $<0.01$ & $9.2(2.8)$ & 0.44 \\
\hline EEM CSA & $17.7(5.3)$ & $18.8(5.9)$ & $<0.01$ & $18.5(5.8)$ & 0.05 \\
\hline I+M CSA & $14.3(5.0)$ & $11.0(4.3)$ & 0.0001 & $11.4(4.5)$ & 0.06 \\
\hline
\end{tabular}

CSA, cross sectional area; EEM, external elastic membrane; $1+M$, intima plus media; MLA, minimum lumen area.

*Significance between results immediately after $\mathrm{PCl}$ versus 98 minutes after $\mathrm{PCl}$.

longitudinal intima shift can explain this phenomenon. However, the expansion of intima tissue was revealed at both the proximal and distal sites of the stent. The majority of loss in lumen CSA at 98 minutes consists of the expansion of the intima tissue, which shrinks by intervention. Although drug eluting stent implantation has been shown to be effective in de novo lesions, the prevention of recurrence of diffuse ISR was insufficient. ${ }^{5}$ The insufficient effect of drug eluting stents for ISR can be explained if smooth muscle cell proliferation does not play a major role in the recurrence of ISR.

In conclusion, significant lumen loss occurred frequently at 98 minutes after successful dilatation of diffuse ISR. This is caused by intima re-intrusion and tissue expansion. These data suggest that the mechanisms for restenosis after treatment for diffuse ISR should be different from that after stenting de novo lesions.

\section{Authors' affiliations}

R lijima, T Tsunoda, M Nakamura, The Third Department of Internal Medicine, Ohashi Hospital, Toho University Faculty of Medicine, Tokyo, Japan
Y Ikari, K Hara, The Division of Cardiology, Mitsui Memorial Hospital, Tokyo

T Yamaguchi, Toranomon Hospital, Tokyo

Correspondence to: Dr R lijima, The Third Department of Internal Medicine, Ohashi hospital, Toho University School of Medicine, 2-17-6 Ohashi Meguro-ku, 153-8515 Tokyo, Japan; raisuke329@aol.com

Accepted 12 December 2003

\section{REFERENCES}

1 Lowe HC, Oesterle SN, Khachigian LM. Coronary in-stent restenosis: current status and future strategies. J Am Coll Cardiol 2002;39:183-93.

2 Hoffman R, Mintz GS, Dussaillant RG, et al. Patterns and mechanisms of instent restenosis: a serial intravascular ultrasound study. Circulation 1996;94:1247-54.

3 Shiran A, Mintz GS, Waksman R, et al. Early lumen loss after treatment of instent restenosis: an intravascular ultrasound study. Circulation 1998;98:200-3.

4 Chung IM, Gold HK, Schwartz SM, et al. Enhanced extracellular matrix accumulation in restenosis of coronary arteries after stent deployment. J Am Coll Cardiol 2002;40:2072-81

5 Liistro F, Stankovic G, Di Mario C, et al. First clinical experience with a paclitaxel derivate-eluting polymer stent system implantation for in-stent restenosis: immediate and long-term clinical and angiographic outcome. Circulation 2002;105:1883-6.

\section{Call for papers}

10th European Forum on Quality Improvement in Health Care

13-15 April 2005, ExCel, Docklands, London

For further information on how to submit your paper please go to:

http://www.quality.bmipg.com 